\title{
Some relevant variables in observational learning of the rat
}

\author{
RICHARD W. GROESBECK, Gonzaga University, Spokane, Wash. 99202 \\ and \\ PRYSE H. DUERFELDT, University of Portland, Portland, Oreg. 97203
}

Several aspects of observational experience were examined to determine their relative contribution to observational learning of rats. Six groups of $10 \mathrm{Ss}$ viewed demonstrator rats perform different aspects of a visual discrimination task for water reinforcement on an elevated $Y$ maze. Ss were then tested for trials and errors to reach criterion on the same task. Modeling aspects of the demonstrator's performance were most important, while vicarious reinforcement had little effect. Informational and following aspects also had impact.

The use of modeling, imitation, or vicarious reinforcement procedures to facilitate the emission of old or the acquisition of new behaviors is not a new problem (Thorndike, 1898; Kinnaman, 1902; Yerkes, 1934; Herbert \& Harsh, 1944), but it has become increasingly important (Bandura, 1962). Explorations of the effectiveness of this technique in modifying human behavior have resulted in numerous theoretical (Miller \& Dollard, 1941; Bandura, 1965 a) as well as practical considerations (Bandura, 1965b; Kanfer, 1967). Recent studies with cats and rats (Johns et al, 1968; Corson, 1967) have also provided additional support for the importance of observational learning in contrast to some earlier negative findings. The important aspects of the observation experience are poorly understood but probably include informational, modeling, and vicarious reinforcement components present in the observational situation.

The purpose of this study was to determine the relative contribution to observational learning of (1) informational content, (2) modeling content, (3) vicarious reinforcement, and (4) a natural tendency to follow.

\section{METHOD}

Sixty male Long-Evans rats between 40 and 60 days old at the beginning of the experiment were assigned randomly to each of five experimental and one control groups. All Ss were separately caged and given dry laboratory chow on an ad lib basis. Five demonstrator $S s$ were acquired prior to the experimental animals and were housed and maintained in the same manner as the experimental Ss.

The apparatus was an elevated $\mathrm{Y}$ maze with a $6 \times 4 \times 4$ in. observation box at the base of the $Y$. The alleys were $4 \mathrm{in}$. wide and $10 \mathrm{in}$. long. Hinged on the floor at the approach to each goal alley was a Plexiglas cue card that could be knocked down easily by a rat pressing his nose or paw against it. The card in front of the corrent alley was diagonally striped, whlle the negative cue card was solid black. The cue cards blocked the view of the goalbox from both the start platform and the observation chamber. At the end of the goal alleys was another cue card identical in pattern to the cue card at the start of the alley. In front of this second striped card was a water bottle which could be seen from both the start platform and the observation box when the cue card was down.

The Ss of all groups were trained in the following manner: On each of 3 days $\mathrm{S}$ was handled for $5 \mathrm{~min}$, on the 4th day $S$ was placed in the observation box for $30 \mathrm{sec}$ and then was placed on the start platform where it was allowed $3 \mathrm{~min}$ to make a choice. If $\mathrm{S}$ did not make a choice, it was placed in a wait box. If $S$ made a incorrect choice it was allowed $15 \mathrm{sec}$ to explore the alley and was then removed. Following a correct choice, $\mathrm{S}$ was allowed to drink for $10 \mathrm{sec}$ before being removed. After each trial $S$ was held in the wait box until the maze was prepared for the next trial. The $S$ was then returned to the observation box for another trial. The position of the arms was counterbalanced for the 12 trials that each $S$ received on a particular day. The maze was wiped with alcohol between the demonstration and the test trial. For all groups except Group 6 the arms were switched one-half of the time between the demonstration and the test trial. All Ss were run to a criterion of 10 consecutively correct trials with a latency less than $10 \mathrm{sec}$.

The same five demonstrators were used throughout the entire study. They were trained on the $\mathrm{Y}$ maze, using a combination of trial-and-error and observational technique until they had achieved 10 consecutive correct trials. An observing rat viewed a different demonstrator each day. If it had not learned the task by the fifth day it would start over with the demonstrator that modeled the task on the first day.

The only difference between the six groups in this study is what occurred during their $30 \mathrm{sec}$ in the observation box. Group 1 was a control group, and no demonstrator was present during the observation period. The stimulus panels remained erect, and $S$ could not see beyond the panels to the water bottle. No cues for observational learning were present.

Group 2 viewed a demonstrator knock the correct panel down, walk over it, and drink water. Information, modeling, and vicarious reinforcement were present for this group. For Groups 2, 3, 4, and 5 the arms of the maze were then reversed one-half of the time between the observation period and the test trial. Thus Ss would not be consistently rewarded for following the demonstrator.

Group 3 Ss watched the demonstrators rewarded on the positive card, but never saw the performance of the task. Hence, only information and vicarious reinforcement were present.

Group 4 Ss watched the demonstrator knock down the panels and go to the water bottle, but, as part of the spout of the water bottle was draped, they could not see the demonstrator drink, and thus the factor of vicarious reinforcement was eliminated. For this group, only the information and modeling aspects were present.

Group $5 \mathrm{Ss}$ viewed $\mathrm{E}$ knock down the correct stimulus panel with a pointer and tap on the water bottle. The only aspect present for this group was information.

Group 6 was used to isolate the following aspect: Ss viewed the demonstrator knock down the stimulus panel, approach the water bottle, and drink. For this group the arms of the maze were not reversed between the observation period and the test trial, thus all the aspects being investigated were present for this group.

Figure 1 shows group learning curves, plotted using the average number of trials to successive criteria. Cochran's test established homogeneity of variance on the mean number of trials to reach the first criterion. A one-way analysis of variance revealed no group differences $(F<1)$, and we may conclude that the groups are equivalent at that point.

The mean number of trials taken to complete 10 consecutive correct trials was examined to determine if there were group differences at the end of training. The number of trials to this final criterion ranged from 17 to 120 for individual Ss, with a mean of 54.8. Following the establishment of 


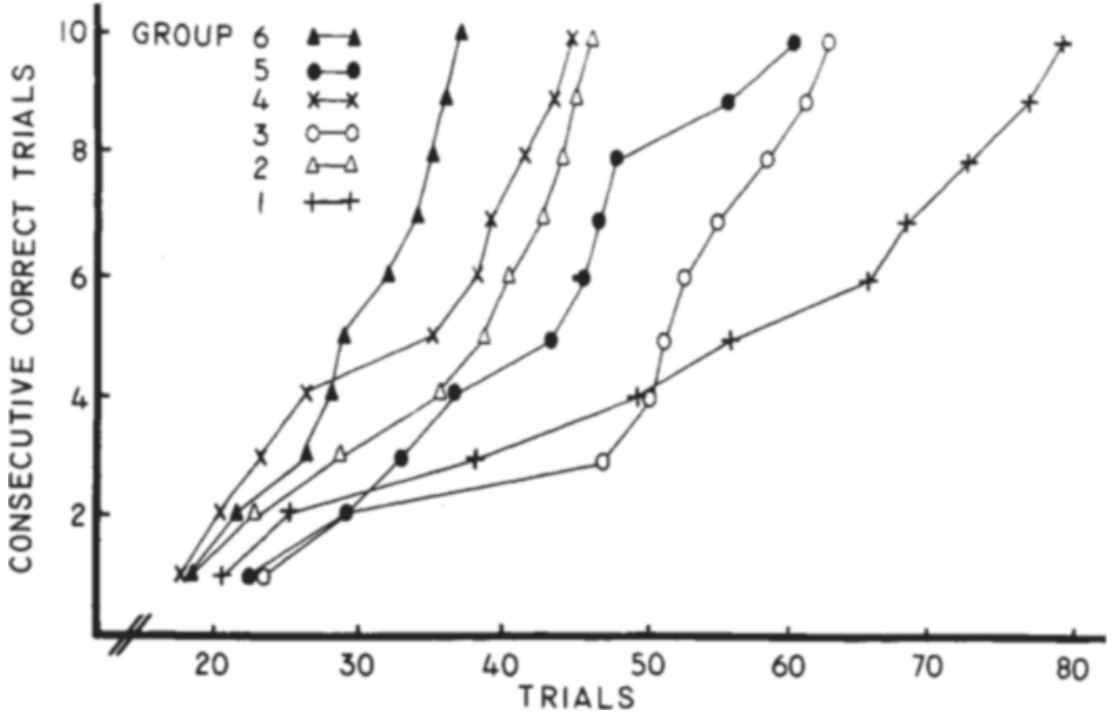

Fig. 1. Mean acquisition curves for all groups.

homogeneity of variance, a one-way analysis of variance revealed significant differences $(\mathrm{F}=4.97, \quad \mathrm{df}=5 / 54$, $\mathrm{p}<.01$ )

A Tukey test (Dixon \& Massey, 1957 , p. 153) revealed the locus of the intergroup differences. Group 1 took more trials to reach criterion than did any other group $(p<.01)$. Thus, all groups exposed to some component of observational learning experience learned more rapidly than did the controls. Group 2 took fewer trials to reach criterion than did Groups 3 and 5 ( $p<.01)$, but did not differ from either Group 4 or Group 6. Groups 3 and 5 took significantly more trials to reach criterion than did Groups 4 and $6(\mathrm{p}<.01)$, but Groups 3 and 5 did not differ from each other. Thus, in terms of speed of reaching criterion, the groups were ordered $6=4=2<5$ $=3<1$.

Cochran's test accepted the hypothesis of equal variance of the natural logarithm of the number of errors made prior to reaching the ultimate criterion $(p<.01)$. An analysis of variance carried out on this transformed data revealed differences among the groups $(\mathrm{F}=5.36$, $\mathrm{df}=5 / 54, \mathrm{p}<.01)$. A post hoc Tukey test localized the differences.

Group 1 made more errors than did any of the other groups $(p<.01)$. Group 2 made more errors than did Group $6 \quad(p<.01)$. Group 3 made more errors than did Groups 4,5 , and $6(p<.01)$. Thus, in terms of the number of errors committed by each group prior to reaching the criterion of 10 consecutive correct trials, the groups were ordered $1<2,3,4,5$, and $6 ; 2<6 ; 3<4=5=6$.

\section{DISCUSSION}

The results of this study show that all of the experimental treatments used facilitated the acquisition of the discrimination task. The $\mathrm{Ss}$ of the experimental groups learned the discrimination task in fewer trials than did the control Ss. Pointing out the relative cues to the $S$ by the $E$ facilitated learning, as did the viewing of a demonstrator's performance.

Generally, this study confirms the finding of Corson (1967) that rats do learn from observing the performance of others. It fails to agree with Corson that the Ss learning through an observational technique were more variable in their performance. The difference in these results may be due to the fact that Corson's control animals were shaped, while those in this study learned by trial and error.

Modeling appeared to be the most important aspect of the observational experience. The three groups that viewed the demonstrator's performance of the discrimination task learned sooner than did the three groups that did not view the demonstrator's performance $(p<.01)$.

The informational aspect was also of value to the Ss. The E's knocking down the stimulus panel and tapping on the spout of the water bottle resulted in Group 5 Ss learning the task with fewer trials than the controls $(p<.01)$. This finding suggests that future Es should not expose their Ss differentially to the learning situation in which they will soon be tested. Most of the studies previously reviewed did not control this factor and, thus, may not have involved observational learning at all. If exposure to the learning situation without a demonstrator provides the same results as exposure with a demonstrator, there is probably a better term to explain the phenomenon than "observational learning." A simple construct such as stimulus enhancement would be more parsimonious.

In this study vicarious reinforcement was operationally defined as the incremental modification in observer performance due solely to viewing a demonstrator drinking. Group 3, which viewed the demonstrator drinking on the positive cue pakel, learned the discrimination in fewer trials than the control group $(\mathrm{p}<.01)$. However, this group did not learn the task in fewer trials than Group 5, which had only the informational aspect available. An analysis of the logarithm of the number of errors before ultimate criterion indicates that $S s$ with the informational component performed better than did Ss who viewed the reinforcement $(p<.01)$. This evidence suggests that the viewing of reinforcement in this situation may have a detrimental effect.

The final observation with respect to vicarious reinforcement is that its removal has no significant effect. Ss who viewed demonstrators perform the water-getting task but who were deprived of viewing the demonstrators drink did not perform differently from Ss who had the opportunity of viewing the reinforcement. Thus it seems that vicarious reinforcement, as defined in this study, was not very important to observational learning. E

It should be noted that the differences found in this study were not present in the first stages of learning as revealed by the analysis of the number of trials to the first correct trial. It is impossible to say from this study whether or not the Ss imitate naturally or are learning to imitate the demonstrator.

In conclusion, rats can learn by observing, and modeling of the demonstrator's performance seems to be the most important variable. Vicarious reinforcement does not seem to be a very good explanatory principle for the phenomenon of observational learning, for here it actually had a detrimental effect upon the observer's learning. Stimulus enhancement and following are important to the phenomenon and should be appropriately controlled so as not to confound the data.

The following component can be evaluated by comparing Groups 2 and 6. For Group 6 the striped panel was always on the side that was demonstrated, whereas for Group 2 the arms of the maze were switched for half of the trials. The mean number of trials to ultimate criterion were not different for the two groups, but the group that always went to the side demonstrated committed fewer errors $(p<.01)$. It would seem that if 
the $S$ is required to perform the task exactly as demonstrated, it does better than if the task varied from the one demonstrated. Following is something that should be controlled in the observational learning experiment. It probably plays less of a role in studies with a Skinner box or a shuttlebox. but in a study with a maze, as this one, it is important. One would not want to attribute more rapid learning of a discrimination task to observational learning if all the $\mathrm{S}$ was doing was following the demonstrator. Two of the Ss of Group 6 were run without the demonstrator after they had reached criterion. They continued to go to the striped panel even though the demonstrator had not modeled the task, thus suggesting that they did learn the discrimination, in addition to learning to follow the demonstrator.

\section{REFERENCES}

BANDURA, A. Social learning through imitation. In M. R. Jones (Ed.), Nebrasko symposium on motivation: 1962 . Lincoln: University of Nebraska Press, 1962. Pp. 211-269.

BANDURA. A. Vicarious processes: A case of no-trial learning. In $\mathrm{L}$. Berkowitz (Ed.), Advances in experimental social psychology'. New York: Academic Press, 1965a. Pp. 1-55

BA NDURA, A. Behavior modification through modeling procedures. In L. Krasner and L. P. Ullman (Eds.), Research in behavior modification. New York: Holt, Rinehart, \& Winston, $1965 \mathrm{~b}$. Pp. 310-340.

CORSON, J. A. Observational learning of a lever pressing response. Psychonomic Science, $1967,7,197-198$.

DIXON, W. \& MASSEY, F, J Introduction to statistical analysis. New York: McGraw-Hill, 1957.

HERBERT, M. J., \& HARSH, C. M. Obersvational learning by cats. Journal of Comparative Psychology, 1944, 37. 81.95.

JOHNS, E. R., CHESLER, P., BARTLETT, F., \& VICTOR, I. Observation learning in cats. Science, 1968, 159, 1489-1491.

KANFER, F. H. Self-regulation. Paper presented at the Ninth Annual Institute for Research in Clinical Psychology, "Behavior Modification in Clinical Psychology," at the University of Kansas, 1967.

KINNAMAN, A, J, Mental life of two Macacus rhesus monkeys in captivity. American Journal of Psychology, 1902 $13,98-149$.

MILLER, N. E., \& DOLLARD, J. Social learning and imitation. New Haven: Yale University Press, 1941.

THORNKIDE, E. L. Animal intelligence. Psychological Review Monograph Supplement, 1898, 2, 1-109.

YERKES, R. M. Suggestibility in chimpanzees. Journal of Social Psychology, 1934,5,272-282.

\title{
The effect of food deprivation on shock elicited aggression in rats
}

\author{
D. D. CAHOON*, RAY M. CROSBY, SANDRA DUNN, M. S. HERRIN, \\ CHARLES C. HILL, and MARCIA McGINNIS \\ Auburn University, Auburn, Ala. 36830
}

Aggressive responses were tabulated for albino rats under conditions of shock stimulation only, food deprivation only, and shock plus food deprivation Results indicated that while deprivation alone did not result in aggression as defined in the experiment, deprivation plus shock elicited more aggression than shock alone. Further, the number of aggressive responses was found to vary positively with amount of deprivation.

A number of experiments have demonstrated that aversive stimulation can elicit aggression in a variety of species, and that the effectiveness of this stimulation is qualified by such variables as the intensity, duration, and mode of punishment (e.g., Ulrich \& Azrin, 1962; Hutchison, Azrin, \& Renfrew, 1968). Few studies, however, have attempted to relate aggression to the degree of deprivation obtaining during the experiment. Azrin, Hutchison, \& Hake (1966)

* Requests for reprints should be sent to D. D. Cahoon, Department of Psychology, Auburn University, Auburn, Alabama 36830 . observed that attack elicited in pigeons by an extinction schedule was reduced by satiation. Davis (1933) reported that rats housed alone, if deprived of food, exhibited attack behavior toward "intruder" rats placed in the home cage when food was present. An experiment by Franchina (1966) suggested that deprivation and aversive stimulation may summate under some conditions. When 0 and $23^{1 / 2} \mathrm{~h}$ of food deprivation were combined with 40 and $70-\mathrm{V}$ shock during an escape trial, performance was directly related to both level of deprivation and shock intensity. On the other hand, Griffiths (1962) demonstrated that 12 - and 24-h food-deprived rats tolerated greater shock intensity than did nondeprived Ss, with 24-h deprivation being related to greater tolerance than the 12 -h period.

The present experiment was designed to determine if food deprivation would increase the number of aggressive responses elicited by electric shock in the albino rat.

\section{SUBJECTS}

Nine experimentally naive male Sprague-Dawley-derived rats from the Auburn University colony were used as Ss. All Ss were approximately 90 days old at the initiation of the experiment.

\section{APPARATUS}

A rat-restraining apparatus with target switch was designed similar to that described by Azrin, Rubin, \& Hutchison (1968). The restraining chamber consisted of a $22 \times 6 \times 6 \mathrm{~cm}$ opaque tube that would not permit the rat to twist or turn when in position. The tube was attached to a flat board and held in place by aluminum braces. A brass tail-restraining rod was fastened to the board at one end of the Plexiglas tube. When a rat was placed in the apparatus a sliding panel with an opening at the base to accommodate the 'Ss' tail enclosed the rear of the tube. This prevented the $S$ from backing out of the chamber but allowed his tail to extend outside of the box. Adhesive tape was used to secure the rat's tail to the restraining rod.

The target was constructed to measure aggression as defined by biting and pulling behavior. This apparatus consisted of a $1 / 2-\mathrm{cm}$-diam doubled brass rod, approximately $7 \mathrm{~cm}$ long, and covered with easily replaceable white adhesive tape at the end nearer the rat. The target was movable and thus could be adjusted with respect to distance from the S's mouth. Biting and pulling the target rod $1 \mathrm{~cm}$ toward the $S$ closed a switch and transmitted an impulse to the recording apparatus.

Shock was delivered to the tail by a constant-current source through external clip electrodes attached to the base and tip of the tail. The rat's tail was kept moist with water during all of the experimental sessions to ensure an adequate electrical contact. Standard programming equipment was used to record the total number of responses for each experimental session and to present shock of a specific duration and intensity at fixed intervals.

\section{PROCEDURE}

Prior to the experiment all Ss were placed in the apparatus for $10 \mathrm{~min}$ to allow for adaptation to the chamber and to measure pretest aggressiveness. Only one rat bit the target during this 